\title{
Pre-Service Primary School Teachers' Mathematical Knowledge for Teaching Fractions through Problem Solving
}

\author{
Samuel Baah-Duodu' ${ }^{1}$, Francis Cornelius Ennin², Seth Borbye ${ }^{3}$, Solomon Amoaddai ${ }^{4}$ \\ ${ }^{1}$ Department of Mathematic/I.C.T
}

Agogo Presbyterian Women's University College of Education

Agogo, Asante-Akyem

Ghana.

\begin{abstract}
This study measured pre-service teachers' mathematical knowledge for teaching (MKT) fractions in Ghanaian basic schools. A Fractional Knowledge Test (FKT) and five-point Likert scale questionnaires were administered to 200 pre-service teachers from two colleges of education (located at Mampong in the Ashanti Region of Ghana) who were conveniently and purposively selected in order to assess their mathematical knowledge on teaching fractions in basic schools. A problem solving ability scale was adapted to assess pre-service teachers' problem solving skills and abilities on fractions through the use of area, set and linear models of fractions. Results of problem solving abilities showed that pre-service teachers' content and pedagogical knowledge on fractions were low. The study revealed that $39.8 \%$ pre-service teachers possess the lowest level (understanding the problem), 35.3\% possess intermediate level (solving the problem) and $24.9 \%$ possess highest level of problem solving. Pre-service teachers lacked the requisite knowledge, skills and expertise for teaching mathematics through problem solving. Pre-service teachers displayed better fractional knowledge on procedure than on conception. The study revealed that pre-service teachers' perception on problems involving fractions positively correlated to their mathematical knowledge for teaching fractions. There was no significant difference by gender, age and mathematical background nor their combinations on pre-service teachers' perception on fractions and their mathematical knowledge for teaching [MKT] fractions. Findings indicated that pre-service teachers need adequate opportunities to practice what they learn in their pedagogy courses in colleges of education. Therefore mathematics pedagogy courses Ghanaian Colleges of Education should be made more practical and pre-service teachers in colleges of education should be given ample opportunity to practice what they are going to teach in basic schools. Pre-service teachers need to develop much and deeper understandings of the mathematics content than they had as students, and their teachers, mathematics teacher educators, must have the knowledge necessary to help with this development.
\end{abstract}

Key Words: Mathematical Knowledge for Teaching, Pre-service Teachers, Fractional Knowledge Test, Problem solving Ability, Content Knowledge, Pedagogical Knowledge.

\section{INTRODUCTION}

Mathematics is one of the important subjects in the list of foundational subjects constituting the core curriculum for basic education in most countries throughout the world. The subject is important because the ability to understand it improves one's chances of social advancement. Notwithstanding, over the past years, children's performance in mathematics has not been impressive as evidenced in National Education Assessment and Trends in International Mathematics and Science [TIMSS] study's report (Anamuah-Mensah, Mereku \& Ghartey- Ampiah, 2008). The importance of fractions is indispensable in mathematics. It is in view of this that fractions form an essential component in the Ghanaian mathematics curriculum from basic education level to tertiary level Curriculum Research 
Development Division [CRDD] (2008). The mathematics curriculum of Colleges of Education places much emphasis on the teaching of fraction in both content and methodology (CRDD, 2008). The inclusion of fractions is to give preservice teachers the requisite pedagogical know-how to teach at the basic level in Ghana. A study on the effect of Ghanaian pre-service teachers' mathematical knowledge for teaching basic school mathematics revealed that the general performance of pre-service teachers on the Mathematical Knowledge for Teaching [MKT] test was low (Nsiah-Asante \& Mereku, 2011). When their responses were analyzed, the mean scores in three content domains were; fractions $(44.0 \%)$, number operations $(40.4 \%)$ and number patterns $(50.2 \%)$.

Fractions are complex in nature and provide important prerequisite conceptual foundations for the growth and understanding of other number types and algebraic operations in later years of children's school experience. Despite the critical conceptual link between mathematics strands involving space and measurement provided by fractions, they continue to present difficulties for children in primary schools (Pitkethly \& Hunting, 1996). Mathematics educators and teachers have invested considerable effort in exploring the instructional value of helping children develop a better grasp of mathematical concepts including fractions. The study of fractions, ratios, and proportions, according to Lamon (2007), is " the most protracted in terms of development, the most difficult to teach, the most mathematically complex, the most cognitively challenging, the most essential to success in higher mathematics and science, and one of the most compelling research sites" (p. 629).

A number of factors have been identified by various researchers and educators as being responsible for children's poor achievement in mathematics such as children's characteristics, instructional and classroom characteristics, teachers' characteristics, societal factors and school factors. Other factors include lack of motivation and poor self-image of school teachers, lack of innovative teaching methods, lack of teaching facilities, poor school climate, lack of incentives and motivation, poor remuneration, poor condition of service and children's poor problem-solving abilities (Moyer, 2001; Moreira \& David, 2008)

In Ghana, the Education Reform Review Committee of ministry of education [MOE] in 2002 recommended a problem solving curriculum for pre-university education. This curriculum took effect in 2007. This current pre-university problem solving mathematics syllabus requires the use of mathematics in solving everyday problems. Specifically, it recommended the application of appropriate mathematical problem-solving strategies in the teaching and learning of mathematics (MOE, 2007). Helping children to acquire the techniques of problem solving therefore becomes one of the main objectives of teaching mathematics in pre-university institutions in Ghana.

\section{STATEMENT OF PROBLEM}

Several researches have revealed that pre-service teachers' understanding of fraction content knowledge is very weak (Nsiah-Asante \& Mereku, 2011; Davis \& Thipkong, 1991; Behr, Khoury, Harel, Post, \& Lesh, 1997; Cramer, Post, \& del Mas, 2002). Evidence has shown that pre-service teachers have difficulties with the concept of fractions and the meaning of division of fractions (Ball, 1990), cannot understand the operator construct of rational number (Behr et al., 1997), have difficulty in explaining fractions to children and why algorithms work (Chinnappan, 2000), and cannot carry out fractional computation procedures correctly, even when they have correct answers (Becker \& Lin, 2005). Pre-service teachers' poor performance in fractions can cause serious problems.

Pre-service teachers will be teaching mathematics in elementary schools or special education programs. It is substantively important issue and should be addressed. Why are fractional numbers difficult for many students and pre-service teachers? Vergnaud (1983) argued fractional number skill development is heavily dependent on other essential elements. Fractional numbers are quite different from the whole numbers. Under different contexts, fractional numbers have different personalities. Fractional numbers have different constructs, i.e. part-whole, quotients, measures, ratio, rate, and operators. A part-whole relationship is the description of how much a quantity is relative to a specified unit of that quantity. A quotient is seeing a fraction number as a result of division. A measure is seeing a fraction as a point on a number line. The fraction as ratio is seeing a fraction as a multiplicative comparison between two quantities. A rate is seeing a fraction as a new quantity as a relationship between two other quantities. Finally, an operator is seeing a fraction as a transformation or as a function for another numbers (Ohlsson, 1988; Lamon, 1999; Steefland, 1987).

Another reason for pre-service teachers' difficulty with fractions might be due to their poor problem solving ability. Problem solving ability referred to students' ability to solve non-routine mathematics problem (Liu, 1993). As Niemi (1996) indicated, there is a closer association between students' level of problem solving ability and their fractional 
knowledge. Thus, research focusing on the relationship between pre-service teachers' problem solving ability and their fraction knowledge would appear to be necessary.

There is an assertion that majority of the children from Sub-Saharan Africa have poor knowledge of basic mathematics facts and weak grasp of mathematics concept as well as enquiry skills that are lower level cognitive competencies (Mereku, 2004). Mathematical knowledge for teaching is an essential ingredient for effective teaching (Ball \& Bass, 2000). Meanwhile, some teachers lack the requisite knowledge, skills and expertise for teaching mathematics through problem solving (Anderson, 2000).

In Ghana, the mathematics syllabus recommends the use of mathematics in daily life by recognizing and applying appropriate mathematics problem solving strategies (MOE, 2007). However, studies have shown that children are not able to solve non-routine mathematical problems (TIMSS, 2003; 2007) and that problem solving is unpopular among Ghanaian children (Mereku, 1998). Children's inability to use appropriate problem solving-strategies to deal with new mathematical situations and the unpopularity of problem solving in schools is a reflection of how mathematics teachers conceive and practice problem solving in the classroom (Nantomah, 2010). Hence, this study is designed to explore pre-service primary teachers' mathematical knowledge and perceptions on problems involving fractions and how they practice problem solving in the content strand of Fractions. Problem solving ability refers to children's ability to solve non-routine mathematics problem (Lester \& Kehle, 2003). Solving problems on fractions requires considerable thinking, but even when pre-service are able, they are not inclined to communicate their thinking. Without such communication how can we reliably assess children's efforts to solve problems involving fractions? Before discussing how to improve communication and assessment, it is useful to clarify the notion of a problem and problem solving. The researcher also believes that effective assessment of problem solving in mathematics requires more than a look at the answer children give. Teachers need to analyze the processes and get children to communicate their thinking. To enhance assessment, this study will devise problem situations and questions that will encourage and motivate pre-service teachers to communicate and explain children's thinking in solving problems involving fractions. Pre-service teachers' weak pedagogical approach to fractions can cause serious problems since they will be teaching mathematics in basic schools.

\subsection{Purpose of the study}

This study is to find out the relationship between the pre-service teachers of Diploma in Basic Education's [DBE] mathematical knowledge on problem solving and their problem solving abilities. The study also examined:

i) Forms and content of teacher knowledge and its influence on instruction.

ii) The influence of Teachers' demographic background on mathematics achievement.

iii) Relationship that exist between pre-service teachers' mathematical knowledge for teaching [MKT] fractions and their problem solving abilities.

\section{RESEARCH QUESTIONS}

1. What knowledge domain do pre-service teachers possess on fractions?

2. What domain of problem solving ability do pre-service teachers possess?

3. Does a relationship exist between pre-service teachers' Content and Pedagogical Knowledge on fractions?

\subsection{Theoretical Framework}

The theoretical framework for this study is based on Shulman's (1986) knowledge domains in teaching. Shulman proposed three knowledge domains for teaching to include: subject matter content knowledge (SMCK), pedagogical content knowledge (PCK). Teaching is far more than mere transmitting of concepts and ideas to learners. It involves bringing out accumulated ideas and experiences children come to class with and working on those ideas and experiences together with the children by way of refining, reorganizing, co-constructing and repairing these ideas and experiences into meaningful and comprehensible form for children to assimilate (Shulman, 2000). This forms the foundation on which teaching mathematics through problem solving leans on. This therefore means that for teachers to teach mathematics through problem solving, they need to have an in-depth understanding of the mathematical content of problem solving, the pedagogical principles of problem solving and curricular materials that inform scope and direction of problem solving. More importantly, they need an integrated knowledge of these knowledge domains. 
According to Shulman (2000), teaching is making what is internal external and this can only be achieved if teachers engage children in the classroom discourse. It is only when children are engaged in an interactive classroom environment that their ideas, conceptions, preconceptions and experiences are made bare to the teacher. Shulman (1986) knowledge domains offer coherent framework for teaching mathematics through problem solving.

\subsection{Problem-solving strategies on Fraction}

Problem-solving strategies are methods that can be used to solve various types of problems (Ontario ministry of Education, 2007). Common problem-solving strategies include: making a model, picture, or diagram; looking for a pattern; guessing and checking; making assumptions; creating an organized list; making a table or chart; solving a simpler problem; working backwards; and using logical reasoning (Ontario ministry of Education, 2007).

Polya (1985) proposed a four-stage problem solving model which involves: understand and explore the problem, find a strategy, use the strategy to solve the problem, look back and reflect on the solution. Although these four stages of problem Solving are listed in order of progression, for difficult problems it may not be possible to simply move through them consecutively to produce an answer. Children may move backwards and forwards between and across the steps in a problem solving process.

According to Polya (1985), there is no chance of being able to solve a problem unless you understand the problem first. Understanding the problem requires not only knowing what to do but also the key pieces of information that somehow need to be put together to obtain the answer. As one will often not be able to absorb all the important information of a problem at once, Polya advised that it is always necessary to read a problem several times both at the start and during working. During the solution process, one may find it necessary to look back at the original question from time to time to make sure that they are on the right path. He further emphasized that understanding the problem can be ensured by asking the following questions in this stage: what is the unknown? What are the data? And what is the condition? Polya's second stage, finding a strategy, tends to suggest that it is fairly simple to think of an appropriate strategy. However, there are certainly problems where children may find it necessary to play around with the information before they are able to think of a strategy that might produce a solution. This exploratory stage will also help children to understand the problem better and become aware of some piece of information that they had neglected after the first reading. At this stage one may ask: Do I know a related problem? And then try to think of a familiar problem having the same or a similar unknown (Polya, 1985). In Polya's third stage, the chosen strategy is used to solve the problem step by step and if the solution cannot be found, the strategy is changed. The final stage involves checking the solution in terms of the original problem to see if the answer is reasonable or not and whether there is another way for the solution or not.

Verschaffel, De Corte, Van Vaerenbergh, Bogaerts and Ratinckx (1999) designed, implemented and evaluated a learning environment that emphasized children' acquisition of an overall meta-cognitive strategy for solving mathematical problems involving five stages. These stages are: (1) build a mental representation of the problem; (2) decide how to solve the problem; (3) execute the necessary calculations; (4) interpret the outcome and formulate an answer; and (5) evaluate the solution. Considering these stages during instruction is helpful and can improve children' problem solving ability. The Institute for The process of solving mathematical problems to include: understanding and defining the problem, exploring the problem, hypothesizing, testing, formalizing, reflecting and evaluating. The most frequent solution strategies are making systematic list, guess and check, drawing diagram, writing equation, looking for pattern, making table, reasoning and simplifying the problem. Success in solving a problem is directly related to the choice of the appropriate strategy (Cai, 2010). Problem-solving strategies discussed above are not finite. Several others are 'invented' in the actual process of solving a problem.

\section{PROCEDURE}

This study employed a mixed-methods design in order to address the research questions. The strategy uses separate quantitative and qualitative methods in order to strengthen one method in areas where the other method is inherently weak (Creswell, 2003). The researcher felt it necessary to include a qualitative measure in addition to a quantitative measure in this study to gain a deeper understanding of pre-service teachers' mathematics knowledge on problem solving. Although collecting test scores of mathematics knowledge on problem solving for the content strands and other variables could easily be done with quantitative measures, the researcher felt the study could be enhanced with qualitative data. 


\subsection{Population and Sample}

There are forty-two (42) public Colleges of Education in Ghana in which seven (10) are in the Ashanti Region. Ashanti region which is located in the southern part of Ghana is the third largest amongst the ten (10) regions. In terms of population, however, it is the most populated region with a population of 3,612,950 in 2000, accounting for 19.1 per cent of Ghana's total population.

The choice of the schools is based on:

(i) Familiarity with Mampong Ashanti;

(ii) Diversity and gender proportionality, for each is a single sex institution

(iii) Easy access to the schools

\subsection{Sample and sampling techniques}

Convenient sampling technique was used to select two Colleges namely; St. Monica's Women's college of Education with student population of 402 and Mampong Men's Technical College of Education with students population of 430. Both colleges are situated in Mampong which is in the Ashanti Region of Ghana. Convenient sampling enables the researcher to reach participants without difficulty (Creswell, 2003).

Purposive sampling was used in the selection of participants for the study. According to Creswell (2003), purposive sampling technique enabled the researcher to reach the participants quickly and to use those participants with very rich experiences to collect meaningful information for deeper understanding. There were 100 students selected from each college making a total of 200 participants. The selection was based on self-voluntary by the participants.

\section{RESEARCH INSTRUMENTS}

Two instruments: fractional knowledge test [FKT] and questionnaire were used to collect data for analysis under the study.

\subsection{Fractional Knowledge Test (FKT)}

The primary data-collection tool was the fractional knowledge test (see Appendix 2).

The Fraction Knowledge Test (FKT) was a test of fraction concepts adapted from Cramer, Post, and del Mas's study (2002). It was modified to provide more emphasis on both pedagogical and content knowledge on the three models for teaching fraction (i.e. Area, Set and Linear models). The FKT consists of six (6) questions in which each question has two parts.

MKT measures have a wide range of questions on various topics but in this particular study only fraction in the DBE mathematics course was considered. This is to say that not all the topics in the DBE mathematics course were covered in this study therefore caution should be exercised in generalizing the results for the entire content of the DBE mathematics course. These items require that teachers respond to mathematical issues that arise in teaching fractions, like assessing pupils' mathematical work, representing fractions and operations in the context of instructions, or explaining common mathematical rules or procedures. All the twelve questions involved mathematical knowledge used to carry out the work of teaching fractions like explaining terms and concepts to students, interpreting students' statements and solution, using representation accurately in the classroom. The assessment instrument for FKT was adopted from Reston (1992).

\subsection{Results/Discussion/Findings}

A Fractional Knowledge Test was conducted to measure pre-service teachers' mathematical knowledge for teaching fractions. The test was basically to determine their content knowledge and pedagogical knowledge on fractions. The test was in two folds, participants were asked to investigate questions, answer them and explain the reasons for their answers. Their solutions to each problem were linked with their content knowledge whiles the explanations to their pedagogical knowledge.

Item like "What fraction is represented by the shaded portion in the figure below?" was deemed as Content knowledge. 


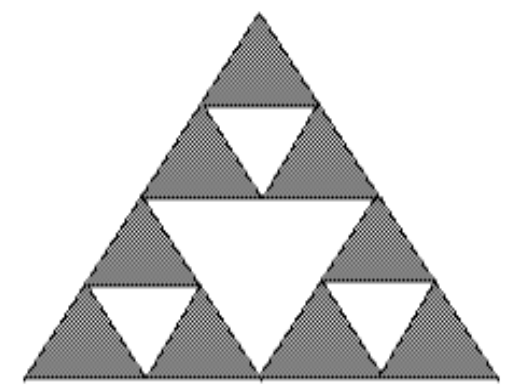

Figure 5.1: Area modelled question on fraction

"Explain how you determined your answer for problem" was deemed as Pedagogical Knowledge. The participants' solutions to the problems were scored using the following scheme:

Content Knowledge: $\quad$ 2-correct answer and correct label of answer,

1-partly correct solution or copying error,

0 -no answer or incorrect solution.

Pedagogical Knowledge: 2-complete understanding of problem,

1-part of problem misunderstood or misinterpreted,

0-complete misunderstanding of problem.

5.3 Mathematical Knowledge for teaching of Participants

Table5.1. Summary of participants' scores on FKT

\begin{tabular}{lccc}
\hline & $\begin{array}{l}\text { CONTENT } \\
\text { KNOWLEDGE }\end{array}$ & $\begin{array}{l}\text { PEDAGOGICAL } \\
\text { KNOWLEDGE }\end{array}$ & $\begin{array}{c}\text { TOTAL MKT } \\
\text { SCORE }\end{array}$ \\
\hline TOTAL SCORE & 2030 & 1270 & 3300 \\
$\%$ SCORE & $42.2 \%$ & $26.5 \%$ & $68.7 \%$ \\
MEAN & 10.15 & 6.35 & 16.5 \\
STDEV & 1.189 & 1.66 & 2.032 \\
\hline
\end{tabular}

\subsection{What knowledge domain do pre-service teachers possess on fraction?}

Table 4.4 reveals the total scores, mean and standard deviation of pre-service teachers' mathematical knowledge for teaching fractions. The results of the test revealed that the general performance of the pre-service teachers on the MKT test was moderate (mean $=68.7 \%, \mathrm{SD}=2.032)$. Their content knowledge on fractions ( mean $=42.2 \%, \mathrm{SD}=1.189)$ was better than that of their pedagogical knowledge on fractions (mean $=26.5 \%, \mathrm{SD}=1.66$ ).

Mathematical problem solving ability scale (MPSAS) was used to assess pre-service teachers' problem solving ability on FKT (see Appendix 3). The results are revealed by the Tables 4.5, 4.6 and 4.7 with respect to gender, age and mathematics background. Results revealed that pre-service teachers' problem solving abilities ranges from the lowest level through the highest level irrespective of their gender, age and mathematics background. 
International Journal of Advances in Scientific Research and Engineering (ijasre), Vol 5 (3), March-2019

Table5.2. Levels of problem solving ability between genders of participants

\begin{tabular}{|c|c|c|c|c|}
\hline \multicolumn{2}{|c|}{ Gender of participants } & understanding the & Solving the Problem & Answering the \\
\hline \multirow[t]{2}{*}{ Male } & Mean & 2.49 & 2.35 & 1.61 \\
\hline & Std. Deviation & 1.068 & .947 & .530 \\
\hline \multirow[t]{2}{*}{ Female } & Mean & 2.70 & 2.26 & 1.64 \\
\hline & Std. Deviation & 959 & .981 & .542 \\
\hline \multirow[t]{2}{*}{ Total } & Mean & 2.59 & 2.30 & 1.62 \\
\hline & Std. Deviation & 1.018 & .963 & .535 \\
\hline
\end{tabular}

It can be found from all the tables that mean scores of participants decreases as their level of problem solving abilities increases. From Table 4.6, participants with higher ages had higher mean values of problem solving abilities.

Does a relationship exist between pre-service teachers' mathematical knowledge for teaching and their problem solving ability?

Table 4.10 shows a statistically significant positive correlation between problem solving ability and MKT scores at Sig $(2-$ Tailed $) \leq .05$. A Pearson's correlation was conducted and a correlation coefficient of 0.864 existed between problem solving ability and MKT scores. The correlation indicates that higher problem solving ability score are related to higher MKT scores. Figure 4.1 shows the graph of the relationship that depicts the positive correlation between MKT scores and problem solving abilities of pre-service teachers.

Table5.3. Correlation between problem solving ability and MKT scores

\begin{tabular}{llcc}
\hline & & Ability & MKT Scores \\
\hline \multirow{2}{*}{ Ability } & Pearson Correlation & 1 & $.864^{* *}$ \\
& Sig. (2-tailed) & .000 \\
& $\mathrm{~N}$ & 200 & 200 \\
MKT Scores & Pearson Correlation & $.864^{* *}$ & 1 \\
& Sig. (2-tailed) & .000 & \\
& $\mathrm{~N}$ & 200 & 200 \\
\hline
\end{tabular}

\section{DISCUSSIONS}

The results of problem solving abilities showed that pre-service teachers' content and pedagogical knowledge on fractions were low. The study revealed that most pre-service teachers possess the first level (understanding the problem) than in the other levels of problem solving abilities. Pre-service teachers lack the requisite knowledge, skills and expertise for teaching mathematics through problem solving (Anderson, 2000). The variations however showed that there are many more pre-service teachers who have difficulty in grasping fractions. Exposing pre-service teachers to variety of fractional models will make meaning of concepts clearer (Lamon, S. J, 2012). 
The Mathematics Problem Solving Ability Scale (MPSAS) showed that pre-service teachers' understanding, solving and answering of problems on fractions were as follows; Understanding fractions $(\bar{x}=2.59, \mathrm{SD}=1.018)$, Solving fractions $(\bar{x}=2.30, \mathrm{SD}=0.963)$ and Answering fractions $(\bar{x}=1.62, \mathrm{SD}=0.535)$. Many pre-service teachers thought they understood fractions because they could perform algorithms for computations with numbers. Having rational number sense means more than just manipulating numbers. It involves attaching meaning to the symbols used, moving easily between representations, understanding and comparing relative sizes of rational numbers, making mental calculations, and recognizing reasonable solutions (CBMS, 2001).

Pre-service teachers in this study were typically familiar with the content of the multiplicative operator, quantitative reasoning, multiplicative reasoning, and proportional reasoning of fractions. There were no significant differences by gender, age and mathematical background on pre-service teachers' problem solving abilities. This was because preservice teachers' mathematical thinking ability is irrespective of gender. The reason for the insignificant difference in pre-service teachers' problem solving ability by age is because their ages were closer to each other and to the mean age of participants involved in the study. Pre-service teachers' mathematical background could not make difference on problem solving ability because problem solving is not taught as a distinct subject in the curriculum. Rather, it cuts across all entire content domains delineated by the curriculum and provides the context in which concepts and skills can be learned. This makes problem solving a primary goal for mathematics instructions and an integral part of all mathematical activity (NCTM, 2000). Using mathematics problem solving assessment scale (MPSAS), to assess preservice teachers' problem solving ability on fractions, the researcher found pre-service teachers' thinking to be procedurally-oriented, focusing on procedures with little or no focus on understanding the process of working with fractions. In a study of pre-service teachers, Ball $(1990 \mathrm{a}, \mathrm{b})$ found that understanding seemed to be composed of only remembering rules for specific cases. The results revealed that pre-service teachers performed well on problems involving area and set models of fractions than in linear models. Pre-service teachers also failed to use mathematical and fractional terms like denominator, equivalence, whole, partitions in their explanations. Pre-service teachers had difficulty justifying their responses and explaining how they arrived at responses. Their knowledge on children's misconceptions was very low especially in FKT question 4, a child was asked what fraction of the bottles is knocked down in this diagram and he said $\frac{3}{7}$ instead of $\frac{3}{10}$ (See appendix 2).

Pre-service teachers were asked to assess the child's answer and interpret it. In their explanation to this problem, preservice teachers failed to recognize that the child took the 3 fallen bottles for numerator which was right but took the standing bottles for denominator instead of the total number of bottles. Probably the child might think that the sum of numerator and denominator should give the total number of bottles. Also in the diagram the bottles seem different comparing the fallen bottle to the standing bottles.

The results of MKT scores revealed that pre-service teachers' Content knowledge ( $\bar{x}=3.8100, \mathrm{SD}=1.42973)$ was better than their curricular knowledge $(\bar{x}=3.1700, \mathrm{SD}=1.284)$ and Pedagogical knowledge $(\bar{x}=2.9450, \mathrm{SD}=1.11724)$.

\section{CONCLUSION}

The primary aim of teaching and learning mathematics is based on the premise that mathematical knowledge can be applied to solve real life problems. As such Ghana's Education Review Committee (MOE, 2002) up to date recommends a problem solving mathematics curriculum for pre-university education. Subsequently, the MOE (2007) revised syllabus emphasized teaching mathematics for real life applications by using problem-solving strategies since 2007 mathematics teachers are expected to teach mathematics through problem solving in order to achieve curriculum objectives.

Teachers' conceptions implicitly inform their decisions in the classroom. It was found in this study that Pre-service primary teachers have diverse conceptions of problem solving as contained in the mathematics curriculum. Four different conceptions of problem solving were identified. Some teachers in this study conceive problem solving as a process of solving difficult mathematical task for which there is no apparent and immediate method of finding the solution. This finding is consistent with NCTM (2000), Hiebert (2003), Lambdin (2003) and Van De Walle (2001, 2003) conception of problem solving. Teachers with this conception in minds believe that there is no problem solving when there is a direct algorithm that can be applied to arrive at the solution. 
In another perspective, problem solving is conceived by teachers in this study as solving mathematical problems which involve real life situations. Earlier study conducted by Saleh (2009) supports this conception of problem solving.

Other pre-service teachers also conceive problem solving as accepting a challenging mathematical problem and striving hard to resolve it. This conception of problem solving is consistent with Dollah (2006) previous finding.

Few teachers in this study conceive Problem Solving as solving open ended problems which lead to open investigations and multiple solutions.

The study disclosed that pre-service teachers see Problem Solving differently even at the point to whether Problem Solving is a "means of finding solution" or a "method of teaching".

The fact that pre-service teachers, who will soon be implementers of Problem Solving in the basic school mathematics curriculum, conceive Problem Solving differently should be seen as national concern because teachers' classroom practices are informed by their conceptions.

Amongst the Problem Solving strategies that are in line with Problem Solving strategies proposed by Polya (1985), and Verschaffel, et at. (1999). These Problem Solving strategies are: understand the problem, devise a plan, carry out the plan, and evaluate the solution process. Problem-solving heuristics such; as draw a table, act the problem, guess and check, trial and improvement and look for pattern were also mentioned by the pre-service teachers. It was found out of the study that majority of the pre-service teachers know much about the strategies and their steps were satisfactory.

\section{REFERENCES}

1. Anamuah-Mensah, J, Mereku, D. K. \& Ghartey-Ampiah, J. (2008). TIMSS 2007, Ghana Report: Findings from IEA's Trends in International Mathematics and Science Study at the Eighth Grade. Accra: Ministry of Education.

2. Curriculum Research Development Division (CRDD), (2008). Ghana mathematics Series, Teaching syllabus for Mathematics (Junior Secondary school), Accra: Ministry of Education.

3. Nsiah-Asante, J. (2011) Pre-service teachers' mathematical knowledge for teaching, Basic school mathematics, Mathematics Connection, 10, 35-48.

4. Lamon, S. J. (2007). Teaching fractions and ratios for understanding: Essential, Content knowledge and instructional strategies for teachers, 3rd ed. p. cm. Includes index.

5. Ministry of Education (2007).Teaching syllabus for Junior High School Mathematics. Curriculum Research and Development Division, Accra.

6. Moyer, P. J. (2001). Are we having fun yet? How teachers use manipulatives to teach mathematics. Educational studies in mathematics: An international journal, 47(2), 75-195

7. Pitkethly, A, \& Hunting, R. (1996). A review of recent research in the area of initial fraction concepts. Educational Studies in Mathematics, 30,5-38.

8. Davis, E. J., \& Thipkong, S. (1991). Preservice elementary teachers' misconceptions in interpreting and applying decimals. School Science and Mathematics, 91(3), 93-99.

9. Behr, M. J., Khoury, H. A., Harel, G., Post, T., \& Lesh, R. (1997). Conceptual units analysis of

a. pre-service elementary teachers' strategies on a rational-number-as operator task. Journal for Research in Mathematics Education, 28(1), 48-69.

10. Cramer, K., Post, T. R., \& del Mas, R. C. (2002). Initial fraction learning by fourth and fifth grade students: A comparison of the effects of using commercial curricula with the effects of using the Rational Number Project curriculum, Journal for Research in Mathematics Education, 33(2), 111-144.

11. Ball, D. L. (1990a). The mathematical understandings that prospective teachers bring to Teacher education. Elementary School Journal, 90, 449-466.

12. Ball, D. L. (1990b). Prospective elementary and secondary teachers' understanding of division. Journal for Research in Mathematics Education, 21, 132-144.

13. Chinnapan, M. (2000). Pre-service teachers' understanding and representation of fractions in a Java Bars environment. ERIC: EJ623921.

14. Becker, J. P. \& Lin, C.Y. (2005). Effects of a computational skills workshop on Pre-service elementary teachers. Preliminary report. Paper presented at the Annual Meeting of the Mathematical Association of American and the American Mathematical Society, Atlanta, GA.

15. Vergnaud, G. (1983). Multiplicative structures. In R. Lesh \& M. Landau (Eds). Acquisition of mathematics concepts and procedures (pp. 127- 174). New York: Academic Press. 
16. Lamon, S. J. (1999). Teaching fractions and ratios for understanding essential content knowledge and instructional strategies for teachers. Mahwah, New Jersey: Lawrence Erlbaum Associates, Publishers.

17. Ohlsson, S. (1988). Mathematical meaning and applicational meaning in the semantics of fractions and related concepts. In J. Heibert \& M. Behr (Eds), Number concepts and operations in the middle grades (pp.53-92). Reston, VA: NCTM.

18. Streefland, L. (1987). Free production of fraction monograpg, In J. C. Bergeron, N. Herscovics, \& C. Kieren (Eds.), Phychology of Mathematics Education, PME XI(Vol. I, pp. 405-410). Montreal : PME.

19. Liu, M. C. (1989). The evaluation report of mathematical problem-solving behavior.National Science Council Report (NSC77-0111-S026-01A), Taipei, Taiwan.

20. Niemi, D. (1996). Assessing conceptual understanding in mathematics: Representation, problem

a. solutions, justifications, and explanations. Journal of Educational Research, 89, 351-364.

21. Anderson, J. A. (2000). An investigation of primary schools teachers' problem-solving beliefs and practices in mathematics classrooms. Thesis submitted to the Faculty of Education, Australian Catholic University in fulfilment of the requirements of the degree of Doctor of Philosophy. Retrieved October 5, 2009 from http://dlibrary.acu.edu.au/digitaltheses/public/adt acuvp198.01072009/index.html

22. Ball, D. L. \& Bass, H. (2000). Interweaving content and pedagogy in teaching and learning to teach: Knowing and using mathematics. In J. Boaler (Ed.), Multiple Perspectives on the Teaching and Learning of Mathematics, 83-104. Westport, CT: Ablex.

23. Mereku, K. D. (2004). 'Methods in Ghanaian Primary Mathematics Textbooks and Teachers' Classroom Practice', Research in Mathematics Education, Volume 6. (Papers of the British Society for Research into learning mathematics). pp157-173.

24. Lester, F. K. \& Kehle, P. (2003). From problem solving to modeling: The evolution of thinking about research on complex mathematical activity.

25. Lo, J. \& Watanabe, T. (1997). Developing ratio and proportion schemes: A story of the fifth Grader. Journal for Research in Mathematics Education, 28, 216-236.

26. Mereku, D. K. (1998). The Language Problem in Problem Solving in Basic SchoolMathematics

27. Nantomah, K. K. (2010). Solving: an investigation of conceptions and practices of Junior high school mathematics teachers. A thesis in the department of Mathematics Education, in partial fulfillment of the requirements for the award of the Degree of Master of Philosophy of the University of Education, Winneba.

28. Shulman, L. S. (1986). Those who understand: knowledge growth in teaching. Educational researcher , 15(2), 4-14.

29. Shulman, L. S. (2000). Teacher development: Roles of domain expertise and pedagogical knowledge. Journal of Applied developmental psychology, 21 (1), 129-135.

30. Ontario Ministry of Education (2007). The Ontario mathematics curriculum. Grades 11 and 12. Retrieved October 5, 2009.

31. Polya, G. (1985). How to solve it: A new aspect of mathematical method. Princeton, N.J.:Princeton University Press.

32. Verschaffel, L., De Corte, E., Lasure, S., Van Vaerenbergh, G., Bogaerts, H., \& Ratinckx ,E. (1999). Learning to solve mathematical application problems: A Design experiment with fifth graders. Mathematical Thinking and Learning, 1, 195229.

33. Cai, J. (2010). Helping elementary students become successful mathematical problem solvers. In D. V. Lambdin \& F. K. Lester (Eds.), Teaching and learning

34. Creswell, J. W. (2003). Research design: Qualitative, quantitative, and mixed method approaches (2 ${ }^{\text {nd }}$ ed.). Thousand Oaks, CA: Sage. Mathematical problem solving (pp. 187202). Hillsdale, NJ: Erlbaum.

35. Cramer, K., Post, T. R., \& del Mas, R. C. (2002). Initial fraction learning by fourth and fifth grade students: A comparison of the effects of using commercial curricula with the effects of using the Rational Number Project curriculum, Journal for Research in Mathematics Education, 33(2), 111-144.

36. Reston, V.A, National Council of Teachers of Mathematics. (1992). Evaluating problem solving in mathematics. Educational leadership, 42-45. 